\title{
TRÊS QUESTÕES RELEVANTES SOBRE A EXECUÇÃO POR MENOR QUANTIA EM FACE DA FAZENDA PÚBLICA SOB A PERSPECTIVA DO DIREITO FUNDAMENTAL À EXECUÇÃO DAS DECISÕES JUDICIAIS ${ }^{1}$
}

\author{
THREE MAIN ISSUES ABOUT SMALL CLAIMS CREDITS AGAINST \\ PUBLIC ADMINISTRATION UNDER THE PERSPECTIVE OF THE \\ FUNDAMENTAL RIGHT OF ENFORCEMENT
}

Diego Martinez Fervenza Cantoario Mestre em Direito Processual pela UERJ. Membro do IBDP. Professor da Escola Superior da Magistratura do Estado do Amazonas (ESMAM). Juiz de Direito (TJAM). Manaus/AM. E-mail: diegofervenza@gmail.com.

RESUMO: Este artigo debate a execução por menor quantia contra a Fazenda Pública sob a perspectiva do direito à execução das decisões judiciais e do princípio da proporcionalidade. Busca-se analisar três questões principais: a ordem cronológica de pagamento, o parcelamento previsto no art. 916 do CPC, e o sequestro de verbas públicas após o prazo para satisfação.

PALAVRAS-CHAVE: Execução contra a Fazenda Pública; requisições de pequeno valor; garantias fundamentais do processo; parcelamento; sequestro.

ABSTRACT: This article debates the enforcement of small claims credits against public entities under the perspective of the fundamental right of enforcement and proportional treatment. We seek to analyze three main issues: the chronological order of payment, the installment payments and the seizure of public money after the deadline for payment.

KEYWORDS: Enforcement against public entities; small amount orders of payment; fair trial rights; installment payments; seizure of public funds.

\footnotetext{
${ }^{1}$ Artigo recebido em 04/01/2021 e aprovado em 21/06/2021.
} 
SUMÁRIO: 1. Introdução. 2. O direito à execução das decisões judiciais no Direito Processual Civil brasileiro. 3. Fundamentos do tratamento diferenciado conferido às requisições de pequeno valor; 4. Submetem-se as requisições de pequeno valor à ordem cronológica de pagamento do art. 100, $\S 3^{\circ}$ da Constituição? 5.É aplicável o parcelamento do art. 916 do Código de Processo Civil às execuções por menor quantia fundadas em títulos executivos extrajudiciais? 5.Limitações ao sequestro de verbas públicas e a pandemia de COVID-19; 6. Conclusão. Referências bibliográficas

\section{Introdução}

É conhecida a distinção entre execução por maior e menor quantia contra a Fazenda Pública. O regime jurídico aplicável a estas execuções, cujo critério diferenciador é o quantum consubstanciado no título executivo, implica na dispensa de submissão das requisições de pequeno valor às regras gerais aplicáveis à execução por maior quantia, que é efetivada através da expedição de precatório.

A não submissão das execuções por menor quantia à expedição de precatórios implica em relevantes alterações na estrutura fundamental da tutela jurisdicional executiva contra os entes públicos, a partir da qual se apresentam três questões relevantes. A primeira é quanto à submissão das requisições de pequeno valor à ordem cronológica de pagamento, estabelecida pelo art. 100, caput, da Constituição. A segunda consiste na possibilidade do executado se valer do parcelamento do art. 916 do Código de Processo Civil, de maneira a satisfazer as execuções por menor quantia em até seis parcelas. Por fim, também se mostra necessário, à semelhança do que já ocorre na execução por maior quantia, de se verificar a admissibilidade da suspensão das ordens de sequestro quando existentes situações excepcionais.

Todas essas questões devem ser compreendidas a partir do direito fundamental à execução das decisões judiciais, cujo conteúdo e impacto na execução por menor quantia será exposto neste breve ensaio. 
Rio de Janeiro. Ano 15. Volume 22. Número 3. Setembro a Dezembro de 2021

Periódico Quadrimestral da Pós-Graduação Stricto Sensu em Direito Processual da UERJ

Patrono: José Carlos Barbosa Moreira (in mem.). ISSN 1982-7636. pp. 263-287 www.redp.uerj.br

\section{O direito à execução das decisões judiciais no Direito Processual Civil brasileiro}

Doutrina e jurisprudência têm reconhecido a existência do direito fundamental à execução das decisões judiciais ${ }^{2}$, que é identificado por Serge Guinchard como uma das grandes garantias do processo justo, ao lado do acesso à justiça. ${ }^{3}$

A jurisprudência das cortes supranacionais de direitos humanos possui grande relevância para a compreensão do tema. No que diz respeito à Convenção Interamericana de Direitos Humanos, é dever de todos os países signatários o respeito ao seu conteúdo, o que se expressa no dever dos juízes dos Estados membros de realizarem o controle de convencionalidade das normas de direito local à luz da Convenção ${ }^{4}$. Por essa razão, a jurisprudência da Corte é essencial para compreender o conteúdo dos direitos previstos na Convenção Interamericana de Direitos Humanos, cujas normas, não obstante a cizânia existente na literatura jurídica, possuem reconhecido caráter supralegal ${ }^{5}$.

Também se mostra essencial a análise da jurisprudência da Corte Europeia de Direitos Humanos quanto ao direito à execução das decisões judiciais, que apesar de não possuir caráter cogente em relação ao Brasil, consiste em importante acervo doutrinário para delimitar o objeto deste estudo, justamente em razão da profundidade da análise empreendida por esta Corte.

A Corte Europeia de Direitos Humanos reconhece que o direito à execução das decisões judiciais decorre do art. $6^{\circ}$ da Convenção, que prevê a cláusula do processo justo. A Corte tem reafirmado a plena eficácia deste direito no que diz respeito às execuções em face dos entes públicos, bem como a impossibilidade de mera alegação destes alegarem insuficiência de recursos como fundamento para o descumprimento ${ }^{6}$. Do mesmo modo, a

\footnotetext{
${ }^{2}$ LÓPEZ GIL, Milagros. Avances en la ejecución de Sentencias contra la Administración. Navarra: Aranzadi, 2004, p. 32-45. MERINO MOLINS, Vicente. CHOLBI CACHÁ, Francisco. Ejecución de sentencias en el proceso contencioso-administrativo e inembargabilidad de bienes públicos: especial referencia a las entidades locales. Valladolid: Lex Nova, 2007, p. 89-133.

${ }^{3}$ GUINCHARD, Serge et al. Droit processuel- Droits fondamentaux du procès. 6. ed. Paris: Dalloz, 2011, p. 1091.

${ }^{4}$ MAZZUOLI, Valério de Oliveira. O controle jurisdicional da convencionalidade das leis no Brasil. In.: SOUSA, Marcelo Rebelo. QUDROS, Fausto de. OTERO, Paulo. PINTO, Vera-Cruz (Org.). Estudos em homenagem ao Professor Doutor Jorge Miranda. Coimbra: Coimbra editora, 2012, v.3, p. 768.

${ }^{5}$ BRASIL. Supremo Tribunal Federal. Tribunal Pleno. Relator: Ministro Cezar Peluso. Recurso extraordinário $\mathrm{n}^{\circ}$. 466.343. Brasília, 3 de dezembro de 2008.

${ }^{6}$ CORTE EUROPEIA DE DIREITOS HUMANOS. Órgão julgador: segunda seção. Relator: S. Naismith. Société de Gestion du Port de Campoloro et Société Fermière de Campoloro contra França. Petição 57516/00. Estrasburgo, 26 setembro de 2006.
} 
Revista Eletrônica de Direito Processual - REDP.

Rio de Janeiro. Ano 15. Volume 22. Número 3. Setembro a Dezembro de 2021

Periódico Quadrimestral da Pós-Graduação Stricto Sensu em Direito Processual da UERJ

Patrono: José Carlos Barbosa Moreira (in mem.). ISSN 1982-7636. pp. 263-287

www.redp.uerj.br

Corte assentou que a ausência de meios executivos idôneos e suficientes para a execução de um título executivo constitui violação ao direito de propriedade, pois o direito material reconhecido em uma decisão judicial integra o patrimônio jurídico do exequente ${ }^{7}$.

A razoável duração do processo também tem sido compreendida como elemento integrante do direito à execução das decisões judiciais, de forma a reconhecer que a fase de concretização do direito deve encontrar seu término em lapso temporal razoável ${ }^{8}$. Se reconhece a alguns créditos, como aqueles decorrentes de obrigações de alimentos, tratamento especial, de maneira a satisfazer a execução em menor tempo 9 .

No âmbito do sistema interamericano, a Corte Interamericana de Direitos Humanos tem considerado os seguintes elementos para determinar a razoável duração de um processo judicial ou administrativo: a) a complexidade do tema; b) a atividade processual do interessado; c) a conduta das autoridades judiciárias; d) o impacto do processo em relação às partes ${ }^{10}$.

No Brasil também se reconhece o direito à execução das decisões judiciais, sobretudo em decorrência dos enunciados normativos dos incisos XXXV e LXXVIII do art. $5^{\circ}$ da Constituição. Deste modo, desde o advento da Constituição de 1988, inúmeros estudos reafirmaram a necessidade de adoção de meios executivos capazes de proporcionar a satisfação do direito material, superando a resistência à atipicidade dos meios executivos ${ }^{11}$,

${ }^{7}$ CORTE EUROPEIA DE DIREITOS HUMANOS. Órgão julgador: segunda seção. Relator: S. Naismith. Société de Gestion du Port de Campoloro et Société Fermière de Campoloro contra França. Petição 57.516/2000. Estrasburgo, 26 setembro de 2006.

${ }^{8}$ LÓPEZ GIL, M. Op. cit., p. 43. SERMET, Laurent. Convention europèenne des droits de l'homme et contentieux administratif français. Paris: Economica, 1996. p. 195.

${ }^{9}$ CORTE EUROPEIA DE DIREITOS HUMANOS. Pretto e outros contra Itália. Petição 7984/77. Estrasburgo, 8 de dezembro de 1983. CORTE EUROPEIA DE DIREITOS HUMANOS. Neusmeister contra Áustria. Petição 1936/63. Estrasburgo, 27 de junho de 1968. CORTE EUROPEIA DE DIREITOS HUMANOS. Scordino contra Itália. Petição 36813/97. Estrasburgo 29 de março de 2006. No mesmo sentido apontamos a Comissão Europeia para a eficiência da justiça sobre a razoável duração dos processos judiciais, que identificada com mais clareza essas características da razoável duração do processo. COMISSÃO EUROPEIA PARA A EFICIÊNCIA DA JUSTIÇA. Lenght of court proceedings in the member states of the Council of the European Court of Human Rights. Estrasburgo, 2006, p. 4-6.

${ }^{10}$ CORTE INTERAMERICANA DE DIREITOS HUMANOS. Caso Valle Jaramillo e outros, par. 155; Caso Radilla Pacheco, par. 244; Caso Comunidade Indígena Xákmok Kásek versus Paraguai. Mérito, Reparações e Custas. Sentença de 24 de agosto de 2010. Série C, n. 214, par. 133.

${ }^{11}$ MARINONI, Luiz Guilherme. Tutela inibitória (individual e coletiva). 4. ed. São Paulo: Revista dos Tribunais, 2006, p. 229. “(...). Entretanto, a tomada de consciência de que os procedimentos não podem ficar distantes do direito material, ou de que devem ser construídas tutelas jurisdicionais adequadas às diversas situações de direito substancial, obrigou ao abandono da idéia de tipicidade das formas executivas, levando às disposições dos arts. 461 do CPC, e 84 do CDC. Tais artigos partem da premissa de que, para o processo tutelar de forma adequada e efetiva as várias situações de direito substancial, é imprescindível não apenas 
e o abandono da dicotomia entre meios sub-rogatórios e coercitivos ${ }^{12}$.

Neste mesmo contexto Marcelo Lima Guerra atentou para a necessidade de juízes interpretarem as normas executivas de modo a conferir-lhes maior efetividade, o que inclui não aplicar normas que imponham restrições a um meio executivo quando tal proceder não for justificável ${ }^{13}$.

Luiz Guilherme Marinoni também sustentou a importância da previsão de meios executivos em abstrato pelo legislador, de forma a assegurar às partes um sistema eficiente de tutela de direitos ${ }^{14}$.

Se a estrutura original do Código de Processo Civil de 1973 foi profundamente alterada durante a sua vigência, de forma a conferir maior eficácia ao direito à execução das decisões judiciais, o Código de Processo Civil de 2015 foi além, de modo a prever expressamente o direito das partes de obterem, em prazo razoável, a tutela do direito material, incluída a atividade satisfativa (CPC, art. $\left.4^{\circ}\right)$. Do mesmo modo, o art. 139, inciso IV, estabeleceu, em tese, amplos poderes aos magistrados para efetivar os seus julgados, inclusive em execuções de obrigações de pagar quantia.

Contudo, pode ocorrer que o direito à execução das decisões judiciais, quando confrontado com outros direitos fundamentais, se submeta a limitações, de maneira a ser necessária a solução do conflito a partir do princípio da proporcionalidade. De fato, ocorrendo tal colisão, notavelmente com os direitos fundamentais do executado, é através da aplicação do postulado da proporcionalidade que se mostrará possível assegurar o núcleo essencial de cada direito em jogo, o que se mostra em conformidade com a teoria relativa, que adotamos neste breve ensaio como referencial ${ }^{15}$.

procedimentos e sentenças diferenciados, mas também que o juiz tenha amplo poder para determinar a modalidade executiva adequada diante do caso concreto"

12 ALVIM NETTO, José Manoel Arruda. WAMBIER, Teresa Arruda Alvim. O grau de coerção das decisões proferidas com base em prova sumária: especialmente a multa. In.:Revista de Processo, São Paulo, $\mathrm{n}^{\circ}$ 142, dezembro/ 2006, p. 13.

${ }^{13}$ GUERRA, Marcelo Lima Direitos Fundamentais e a proteção do credor na execução civil. São Paulo: Revista dos Tribunais, 2003, p. 102-105.

${ }^{14}$ MARINONI, Luiz Guilherme. Tutela inibitória (individual e coletiva). 4. ed. São Paulo: Revista dos Tribunais, 2006, p. 14.

15 "As teorias subjetivas acerca do conteúdo essencial podem ser absolutas ou relativas. Segundo a teoria relativa, o conteúdo essencial é aquilo que resta após o sopesamento. Restrições que respeitem a máxima da proporcionalidade não violam a garantia do conteúdo essencial nem mesmo se, no caso concreto, nada restar do direito fundamental. A garantia do conteúdo essencial é reduzida à máxima da proporcionalidade. (...)”. ALEXY, Robert. Teoria dos direitos fundamentais. $2^{\text {a }}$ ed. Trad.: Virgílio Afonso da Silva. São Paulo: Malheiros, 2017, p. 297/298. 
A questão apresenta menor dificuldade quando tal operação é realizada pelo próprio legislador, como ocorre nas hipóteses de impenhorabilidade, tais como: bem de família (Lei $\mathrm{n}^{\circ}$. 8.009 de 1990, art. $1^{\circ}$ ); vencimentos do executado (CPC, art. 833, inciso IV); seguro de vida (CPC, art. 833, VI); pequena propriedade rural, assim definida em lei, desde que trabalhada pela família (CPC, art. 833, inviso VIII). Todas essas limitações decorrem da necessidade de proteger o núcleo essencial de direitos fundamentais, como a dignidade do executado e o direito ao patrimônio jurídico mínimo, em contraponto ao direito à execução das decisões judiciais ${ }^{16}$.

Contudo, não é possível que o legislador esgote todas as situações que podem se verificar no dia a dia, o que fica evidenciado em um ordenamento jurídico caracterizado como multinível ${ }^{17}$. Por essa razão é relevante que se considere a apreciação da colisão de princípios mediante uma relação de precedência condicionada entre os princípios, conforme sustentado por Alexy ${ }^{18}$. Assim, mostra-se essencial o postulado da proporcionalidade ${ }^{19}$, para a solução dos casos concretos que envolvam colisão de direitos fundamentais na tutela jurisdicional executiva.

Como sabido, a proporcionalidade se desenvolve a partir da aplicação de três máximas parciais, quais sejam, adequação, necessidade e proporcionalidade em sentido estrito.

A adequação, conforme a lição de Humberto Ávila, “exige uma relação empírica ente o meio e o fim" ${ }^{20}$. Deve ser considerada a relação entre os meios existentes sob três aspectos: quantitativo (intensidade), qualitativo (qualidade) e probabilístico (certeza) ${ }^{21}$.

O segundo elemento, necessidade, o pode ser definido como "a existência de meios que sejam alternativos àquele inicialmente escolhido pelo Poder Legislativo ou Poder

\footnotetext{
${ }^{16}$ DIDIER JÚNIOR, Fredie. Subsídios para uma teoria das impenhorabilidades. In.: Revista de Processo, São Paulo, vol. 174, agosto de 2009, p. 40. "A impenhorabilidade de certos bens é uma restrição ao direito fundamental à tutela executiva. É técnica processual que limita a atividade executiva e que se justifica como meio de proteção de alguns bens jurídicos relevantes, como a dignidade do executado, o direito ao patrimônio mínimo e a função social da empresa. São regras que compõem o devido processo legal, servindo como limitações políticas à execução forçada".

${ }^{17}$ CARRATA, Antonio. Decisione robotica e valori del processo. Anno LXXV (Seconda Serie) - N. 2 Aprile-Giugno 2020. Rivista di Diritto Processuale. Padova: CEDAM, p. 499.

${ }_{18}$ ALEXY, Robert. Teoria dos direitos fundamentais. $2^{\mathrm{a}}$ ed. Trad.: Virgílio Afonso da Silva. São Paulo: Malheiros, 2017, p. 96.

${ }^{19}$ Utilizamos a nomenclatura utilizada por Humberto Ávila. ÁVILA, Humberto. Teoria dos Princípios. $6^{\mathrm{a}}$ ed. São Paulo: Malheiros, 2006, p. 129.

${ }^{20}$ ÁVILA, H. Op. Cit. p. 152.

${ }^{21}$ Ibid, p. 153.
} 
Executivo, e que possam promover igualmente o fim, sem restringir, na mesma intensidade, os direitos fundamentais afetados" 22 . É preciso, portanto, que ocorra o confronto entre as diferentes alternativas existentes para a concretização do direito material.

Por fim, a proporcionalidade em sentido estrito: "exige a comparação entre a importância da realização do fim e a intensidade da restrição aos direitos fundamentais"23.

Adiante, analisaremos de que forma o direito à execução das decisões judiciais se relaciona com as normas referentes às execuções por menor quantia, tradicionalmente denominadas de requisições de pequeno valor.

\section{Fundamentos do tratamento diferenciado às requisições de pequeno valor}

A Emenda Constitucional no ${ }^{\circ} .20$ de 1998, introduziu significativa alteração no regime de satisfação das execuções contra os entes públicos. A partir da inserção do art. $100, \S 3^{\circ}$, ao texto constitucional, excepcionou-se o regime de precatórios em relação aos créditos tidos como de pequeno valor, cuja satisfação deveria ser imediata, ou seja, sem expedição de precatório $^{24}$.

A requisição de pagamento não se distingue ontologicamente do precatório, pois também consiste em uma ordem de pagamento ${ }^{25}$. Contudo, ao contrário daquele, prescinde de dotação orçamentária específica, de forma a tornar desnecessário aguardar a inclusão de verbas destinadas ao pagamento do crédito no orçamento do ente público ${ }^{26}$.

É certo, conforme aponta a literatura processual, que existe uma relação de especialidade dos procedimentos que disciplinam a tutela jurisdicional executiva contra a Fazenda Pública, quando considerados os procedimentos comuns de cumprimento de sentença e execução de título executivo extrajudicial previstos no Código de Processo Civil $^{27}$. Contudo, é preciso atentar que também existirá essa relação da tutela executiva das

\footnotetext{
${ }^{22}$ Ibid, p. 158.

${ }^{23} \mathrm{Ibid}$, p. 160.

${ }^{24}$ FONSÊCA, Vitor. Requisição de pequeno valor. In: SANTOS, Ernane Fidélis dos. WAMBIER, Luiz Rodrigues. NERY JR., Nelson. WAMBIER, Teresa Arruda Alvim. Execução Civil: estudos em homenagem ao professor Humberto Theodoro Júnior. São Paulo: Revista dos Tribunais, 2007, p. 375.

${ }^{25}$ BRASIL. Superior Tribunal de Justiça. Órgão julgador: Corte Especial. Relator: Ministro Luiz Fux. Recurso Especial 1143677/RS. Brasília, 02.12.2009.

${ }^{26}$ FONSECA, V. Op. cit., p. 375.

${ }^{27}$ DIDIER JR., Freddie. CABRAL, Antônio do Passo. CUNHA, Leonardo José Carneiro da. Por uma nova teoria dos procedimentos especiais. Salvador: Juspodivm, 2018, p. 23.
} 
obrigações de pequeno valor quando considerada a execução por precatório - àquela é especial em relação a esta.

A satisfação da execução em sentido lato (ou seja, tanto a execução de título extrajudicial quanto o cumprimento de sentença), deverá ser realizada dentro de dois meses, contados a partir da entrega da requisição (CPC, art. 535, § $3^{\circ}$, inciso II e art. 910, § $3^{\circ}$ ), sob pena de sequestro (Lei $\mathrm{n}^{\mathrm{o}} 10.259$ de 2001, art. 17, § $2^{\circ}$ e Lei $\mathrm{n}^{\circ} .12 .153$ de 2009, art. 13, § $\left.1^{\circ}\right)^{28}$. Não há necessidade de se aguardar o exercício financeiro subsequente para a satisfação da execução.

O legislador, neste ponto, abraçou prestigiosa doutrina, capitaneada por Vicente Greco Filho, que desde antes da Constituição de 1988 defendia que créditos de pequena monta recebessem tratamento diferenciado, de modo a evitar espera excessiva para o recebimento $^{29}$.

João Pereira Monteiro Neto identifica três fundamentos para o modelo diferenciado na satisfação das execuções através de requisições de pequeno valor: (a) simplicidade para a disponibilização dos valores; (b) menor impacto sobre o erário, pois os valores são menores do que aqueles consubstanciados em precatórios; (c) necessidade de conferir maior efetividade aos credores das requisições de pequeno valor ${ }^{30}$.

De fato, o tratamento diferenciado conferido aos créditos de pequena monta se justifica em razão do óbice ao acesso à justiça que poderia constituir a submissão destes credores ao regime de precatórios. O longo tempo de espera, decorrente do regime adotado pela Constituição, consistiria em relevante fator de desestímulo ao ajuizamento de demandas contra os entes públicos ${ }^{31}$.

\section{Submetem-se as requisições de pequeno valor à ordem cronológica de pagamento}

\footnotetext{
${ }^{28}$ A constitucionalidade do prazo de dois meses para a satisfação das execuções sujeitas a requisição de pequeno valor foi confirmada pelo STF no julgamento da ADI 5534. BRASIL. Supremo Tribunal Federal. Relator: Ministro Dias Toffoli. Órgão julgador: plenário. ADI 5534. DJE, 8/01/2020.

${ }^{29}$ GRECO FILHO, Vicente. Da execução contra a Fazenda Pública. São Paulo: Saraiva, 1986, p. 20.

${ }^{30}$ MONTEIRO NETO, João Pereira. Execução contra a Fazenda Pública. São Paulo: Tirant lo Blanch, 2020, p.73.

${ }^{31}$ Merece menção a crítica de Marçal Justen Filho, para quem não haveria justificativa para se estabelecer um critério diferenciado fundado no valor da dívida. JUSTEN FILHO, Marçal. Emenda Constitucional n. 62/2009: Estado Democrático de Direito e Responsabilidade Civil do Estado. In: JUSTEN FILHO, Marçal. NASCIMENTO, Carlos Valder. Emenda dos precatórios. Fundamentos de sua inconstitucionalidade. Belo Horizonte: Fórum, 2010, p. 172.
} 


\section{do art. 100, caput, da Constituição?}

A ordem cronológica de pagamento exerceu uma importante função desde a instituição do regime de precatórios. Se antes da Constituição de 1934 o pagamento das condenações judiciais contra a Fazenda Pública era marcado pela advocacia administrativa ${ }^{32}$, com a constante preterição de exequentes ao sabor do critério da maior influência política, a instituição da ordem cronológica de satisfação assegurou o tratamento isonômico entre as partes, em respeito aos princípios da moralidade administrativa e impessoalidade.

Por essa razão, a literatura jurídica sustenta que a satisfação das execuções através de precatórios submetidos a ordem de pagamento é meio idôneo a resguardar a isonomia entre credores, de forma a impedir que alguns possam desfrutar de recebimento mais célere dos valores em razão de maior influência perante o establishment ${ }^{33}$.

Considerando-se as normas da execução por maior quantia, é adequado que a satisfação das execuções contra os entes públicos ocorra através da observância da ordem cronológica de expedição de precatórios, pois o prazo constitucional para o pagamento, bem como os sucessivos parcelamentos (como por exemplo, os promovidos pelos arts. 33, $78 \mathrm{e}$ 97 do ADCT), pode alongar o pagamento por anos ou décadas. Nesse contexto, a satisfação antecipada de execuções, de acordo com a preferência dos administradores públicos, violaria o direito fundamental à execução das decisões judiciais, pois não observaria a igualdade na previsão de meios executivos, assegurando a alguns exequentes a satisfação em prazo razoável, e a outros não, sem qualquer critério objetivo de distinção.

Ademais, impedindo-se o administrador escolher quem receberá em primeiro lugar, confere-se efetividade aos princípios da moralidade e legalidade ${ }^{34}$.

Contudo, diferentemente do precatório, a requisição de pequeno valor não se submete ao requisito da ordem cronológica de pagamento, o que decorre de expressa previsão

\footnotetext{
${ }^{32}$ SOUTO, João Carlos. A União Federal em juízo. 3. ed. Rio de Janeiro: Lumen Juris, 2006, p. 305. NUNES, Castro. Da Fazenda Pública em juízo. Rio de Janeiro: Freitas Bastos, 1950. p. 228-229.

${ }^{33}$ LEMOS, Bruno Espiñeira. Precatório. Trajetória e desvirtuamento de um instituto. Porto Alegre: Sergio Fabris, 2004, p. 51-53. FONSÊCA, Vitor. Requisição de pequeno valor. In: SANTOS, Ernane Fidélis dos. WAMBIER, Luiz Rodrigues. NERY JR., Nelson. WAMBIER, Teresa Arruda Alvim. Execução Civil: estudos em homenagem ao professor Humberto Theodoro Júnior. São Paulo: Revista dos Tribunais, 2007. p. 373.

$34 \quad$ LEMOS, B. E. Op. cit., p. 51-53.
} 
Rio de Janeiro. Ano 15. Volume 22. Número 3. Setembro a Dezembro de 2021

Periódico Quadrimestral da Pós-Graduação Stricto Sensu em Direito Processual da UERJ

Patrono: José Carlos Barbosa Moreira (in mem.). ISSN 1982-7636. pp. 263-287 www.redp.uerj.br

constitucional (Constituição, art. 100, $\S 3^{\text {o }}$ ) $^{35}$. Não é por outra razão que as requisições de pequeno valor são expedidas diretamente pelo juiz da execução ao ente devedor (CPC, art. $535, \S 3^{\circ}$, inciso II), e não pelo presidente do tribunal, que possuiria meios para gerenciar a ordem cronológica dos diferentes entes executados, como ocorre na execução por maior quantia (Constituição, art. 100, $\S 6^{\circ}$ ). Além disso, a satisfação pelo ente público, na primeira hipótese, ocorre mediante depósito na agência de banco oficial mais próxima da residência do exequente (CPC, art. 535, $\S 3^{\circ}$, inciso II), e não através de dotações orçamentárias e créditos consignados diretamente ao Poder Judiciário (Constituição, art. 100, $\S 6^{\circ}$ ), o que por si só evidencia a impossibilidade do juiz da execução de exercer qualquer controle quanto a ordem de pagamento das requisições de pequeno valor.

Apesar da previsão legal de que a requisição de pequeno valor é expedida pelo juiz da execução, na Justiça Federal o juiz deve expedir ofício requisitório ao presidente do tribunal regional federal, que organizará mensalmente a relação das requisições em ordem cronológica, com os valores por beneficiário, encaminhando-a à Secretaria de Planejamento, Orçamento e Finanças do Conselho da Justiça Federal, e ao representante legal da entidade devedora (Resolução nº 458 do Conselho da Justiça Federal, art. $3^{\circ}, \S 1^{\circ}$ e art. $6^{\circ}$ ).

Ainda no âmbito da Justiça Federal, quando executados a Fazenda estadual, distrital, municipal, suas autarquias e fundações, conselhos profissionais, bem como a Empresa Brasileira de Correios e Telégrafos, dispõe o art. $3^{\circ}$, § $2^{\circ}$, da Resolução ${ }^{\circ}$. 458, do Conselho da Justiça Federal, que as requisições serão encaminhadas pelo juízo da execução ao próprio devedor, fixando-se o prazo de 60 (sessenta dias) para o respectivo depósito diretamente na vara de origem.

No âmbito dos tribunais de justiça, a regra é a inexistência de normas semelhantes

\footnotetext{
${ }^{35}$ No mesmo sentido a jurisprudência do Superior Tribunal de Justiça. BRASIL. Superior Tribunal de Justiça. Corte Especial. Agravo regimental nos embargos de divergência em recurso especial nº ${ }^{\circ}$ 1149594/RS. Relator: Ministro Luiz Fux. Brasília, 6.10.2010. No mesmo sentido: BRASIL. Tribunal de Justiça do Estado de São Paulo. Agravo de Instrumento 2127232-68.2017.8.26.0000; Relator (a): Marcos Pimentel Tamassia; Órgão Julgador: $1^{\text {a }}$ Câmara de Direito Público; Foro de Rio das Pedras - Vara Única; Data do Julgamento: 22/09/2017; Data de Registro: 22/09/2017. Na doutrina ressaltamos o entendimento de Fredie Didier Jr., Leonardo Carneiro da Cunha, Paula Sarno Braga, e Rafael Alexandria de Oliveira. DIDIER JR., Fredie. CUNHA, Leonardo Carneiro da. BRAGA, Paula Sarno. OLIVEIRA, Rafael Alexandria. Curso de direito processual civil. V. 5. $8^{\mathrm{a}}$ ed. Salvador: Juspodivm, 2018, p. 691. "No caso de condenação de pequeno valor, não há exigência constitucional de observância da ordem cronológica. Logo a Fazenda Pública pode, nas hipóteses de pequeno valor, efetuar pagamento voluntário. Sendo assim, é possível valer-se do expediente previsto no art. 526 do $\mathrm{CPC}$ e, antecipando-se à intimação para pagamento, já efetuá-lo no valor que entende devido. Mas isso, não custa repetir, só é possível nos casos em que a condenação for de pequeno valor”.
} 
àquela que determina a organização de relação de requisições em ordem cronológica pelo presidente do tribunal regional federal. Assim, por exemplo, a Portaria ${ }^{\circ}$. 720 de 16 de março de 2020, do Tribunal de Justiça do Estado do Amazonas, estabelece que as requisições de pequeno valor serão dirigidas pelo juiz da execução à entidade devedora.

Parcela da doutrina elogia a normativa do Conselho da Justiça Federal, que foi antecedida por outras de idêntico teor, afirmando que estes dispositivos buscam permitir que, também com relação às requisições de pequeno valor, possa ser observada a ordem cronológica de pagamento, de modo a assegurar o respeito aos princípios da igualdade e da moralidade administrativa ${ }^{36}$.

Não obstante o escopo de respeito a princípios de estatura constitucional, a Resolução $n^{\circ}$. 458 do Conselho da Justiça Federal dispôs em sentido contrário ao estabelecido pelo Código de Processo Civil, que prevê como atribuição do juiz da execução a expedição da requisição de pequeno valor, sem intermediação do presidente do respectivo tribunal (CPC, art. 535, $\S 3^{\circ}$, inciso II). Conforme já exposto, tal previsão legal decorre diretamente da exceção estabelecida pela própria Constituição para as execuções por menor quantia. Acreditamos que o enunciado normativo do art. 535, $\S 3^{\circ}$, inciso II do Código de Processo Civil não traz prejuízos à igualdade, ou à moralidade administrativa, pois sempre será permitido ao exequente se valer do sequestro caso não satisfeita a execução no prazo de dois meses, inexistindo a necessidade da observância estrita de ordem cronológica. A existência de meios sub-rogatórios a disposição dos exequentes, bem como o reduzido prazo para satisfação, torna despicienda a preocupação com a ordem cronológica de pagamento.

Outro aspecto reforça a opção do constituinte derivado de excetuar as requisições de pequeno valor do controle da ordem cronológica: a não submissão aos parcelamentos impostos pela Constituição. Assim, a Emenda Constitucional no ${ }^{\circ} 30$ de 2000, que parcelou a satisfação das execuções cujos precatórios estivessem pendentes, bem como aquelas decorrentes de ações propostas até 31 de dezembro de 1999, excluiu as requisições do parcelamento previsto no art. 78, caput, do ADCT. Do mesmo modo, as Emendas Constitucionais subsequentes, quais sejam, $n^{\circ} .37$ de 2002, $n^{\circ} .62$ de 2009 e $n^{\circ} .94$ de 2016, excluíram as requisições de pequeno valor do regime especial por ela instituído (respectivamente art. 86, inciso II; art. 97, caput; e art. 101 do ADCT), a primeira

\footnotetext{
${ }^{36}$ FONSECA, V. Op. cit., p. 377.
} 
expressamente, e a segunda a partir da intepretação a contrario sensu do caput, que apenas se refere aos precatórios, deixando de mencionar as requisições de pequeno valor. Portanto, os entes públicos devem satisfazer as execuções por menor quantia no prazo de dois meses (CPC, art. 525, $\S 3^{\circ}$, inciso II), submetendo-se ao sequestro no caso de descumprimento. Ademais, não se submeterão ao parcelamento previsto nos dispositivos constitucionais, o que afasta a possibilidade de violação à razoável duração do processo em decorrência de eventual satisfação de execução em desconformidade com a ordem de apresentação das requisições.

Por essa razão, a não submissão das requisições de pequeno valor à ordem de pagamento não violam o direito das decisões judiciais, na medida em que não será possível a preterição dos exequentes em situação semelhante, pois em hipóteses tais o legislador dotou o juiz de plenos poderes sub-rogatórios em face dos entes públicos.

\section{5. É aplicável o parcelamento do art. 916 do Código de Processo Civil às execuções por menor quantia fundadas em títulos executivos extrajudiciais?}

O Código de Processo Civil permite ao executado requerer a satisfação da execução de forma parcelada, em até 6 (seis) depósitos mensais, acrescidos de juros de um por cento ao mês (CPC, art. 916). Exige-se do executado o reconhecimento do crédito, com a consequente renúncia aos embargos, e o depósito de trinta por cento do valor em execução, acrescido de custas e honorários de advogado.

O parcelamento beneficia ambas as partes da relação jurídico processual. Do ponto de vista do autor, incentiva a satisfação da execução, mediante o acréscimo de lapso temporal razoável. Por outro lado, pela perspectiva do réu, evita que este precise se socorrer de instituições financeiras, em condições menos favoráveis, para obter os valores necessários à 
Revista Eletrônica de Direito Processual - REDP.

Rio de Janeiro. Ano 15. Volume 22. Número 3. Setembro a Dezembro de 2021

Periódico Quadrimestral da Pós-Graduação Stricto Sensu em Direito Processual da UERJ

Patrono: José Carlos Barbosa Moreira (in mem.). ISSN 1982-7636. pp. 263-287

www.redp.uerj.br

satisfação da execução ${ }^{37}$. Sua finalidade é a louvável redução da litigiosidade ${ }^{38}$.

Não há dúvidas de que o parcelamento também encerra, ainda que indiretamente, uma coerção indireta, na medida em que traz incentivo para a satisfação da execução ${ }^{39}$. Deste modo, o outrora recalcitrante executado, que poderia sentir-se tentado a não satisfazer a execução, em razão da necessidade de imediatamente imobilizar parcela do seu patrimônio, pode inclinar-se a requerer o parcelamento, que encerra condições mais benéficas. $\mathrm{O}$ seu reconhecido caráter coercitivo também evidencia uma das marcas características da execução em nosso tempo: a superação da dicotomia entre meios de coerção e meios subrogatórios, em benefício da tutela do direito material ${ }^{40}$.

Apesar da controvérsia que grassou a doutrina, prevalece o entendimento de que o parcelamento consiste em direito subjetivo do executado ${ }^{41}$.

Sua natureza, de acordo com Freddie Didier Jr. e Antônio Cabral será de negócio

\footnotetext{
${ }^{37}$ CARNEIRO, Athos Gusmão. Cumprimento da sentença civil e procedimentos executivos. $2^{\circ}$ ed. Rio de Janeiro: Forense, 2011, p. 233. Também destaca a importância do instituto para a efetividade da tutela executiva Humberto Theodoro Júnior, em obra que tratou do tema ainda sob a égide do CPC 1973: "O novo art. 745-A institui uma espécie de moratória legal, como incidente da execução do título extrajudicial por quantia certa, por meio do qual se pode obter o parcelamento da dívida. A medida tem o propósito de facilitar a satisfação do crédito ajuizado, com vantagens tanto para o executado quanto para o exequente. O devedor se beneficia com o prazo de espera e com o afastamento dos riscos e custos da expropriação executiva; e o credor, por sua vez, recebe uma parcela do crédito, desde logo, e fica livre dos percalços dos embargos do executado. De mais a mais, a espera é pequena - apenas seis meses no máximo - um prazo que não seria suficiente para solucionar os eventuais embargos do executado e chegar, normalmente, à expropriação dos bens penhorados e à efetiva satisfação do crédito ajuizado". THEODORO JÚNIOR, Humberto. A reforma da execução do título extrajudicial. Rio de Janeiro: Forense, 2007, p. 216.

${ }^{38}$ BARIONI, Rodrigo. O parcelamento do crédito do exequente no novo CPC. In.: Revista de Processo. São Paulo: Revista dos Tribunais, 2015, ano 40, n. 244, Junho/2015, p. 162.

${ }^{39}$ DIDIER JR., Fredie. BRAGA, Paula Sarno. CUNHA, Leonardo Carneiro da. OLIVEIRA, Rafael Alexandria

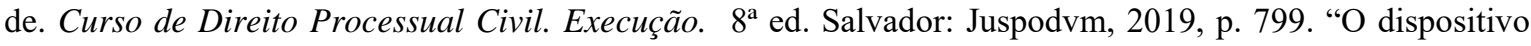
confere uma espécie de favor legal ao executado, na execução de título extrajudicial (art. 916, § $7^{\circ}$, CPC). Trata-se de estímulo ao cumprimento espontâneo da obrigação: uma medida legal de coerção indireta pelo incentivo à realização do comportamento desejado (adimplemento), com a facilitação das condições para que a dívida seja adimplida".

${ }^{40}$ CANTOARIO, Diego Martinez Fervenza. Execução por quantia certa contra a Fazenda Pública. $2^{\mathrm{a}}$ ed. Curitiba: Juruá, 2016, p. 52/54

${ }^{41}$ NASSER, Paulo Magalhães. SANTOS, Welder Queiroz dos. A postura ativa do devedor na execução e a necessidade de análise do risco envolvido. In.: Execução civil e temas afins. Do CPC/1973 ao Novo CPC. Estudos em homenagem ao professor Araken de Assis. ALVIM, Arruda et alii (Org.). São Paulo: Revista dos Tribunais, 2014, p. 857. MAZZEI, Rodrigo. Notas sobre a possibilidade de pagamento parcelado na execução extrajudicial. In.: Execução. $2^{a}$ ed. Org.: DIDIER JR., Fredie. MACÊDO, Lucas Buril. PEIXOTO, Ravi. FREIRE, Alexandre. Salvador: Juspodium, 2016, p. 577. "Com efeito, o art. 916 é uma opção que pode ou não ser exercida (direito potestativo) pelo executado, por meio de ato volitivo, em processo judicial (execução de títulos extrajudiciais) e vinculado ao preenchimento de requisitos formais (descrito no caput do dispositivo)". FARIAS, Marcela Kohlbach de. Negócios jurídicos processuais unilaterais e o requerimento de parcelamento do débito pelo executado. In.: CABRAL, Antônio do Passo. NOGUEIRA, Pedro Henrique. Negócios Processuais. $3^{\text {a }}$ ed. Salvador: Juspodvm, 2017, p. 433.
} 
unilateral de eficácia mista, material e processual ${ }^{42}$. De fato, não há dúvidas de que o parcelamento independe da vontade do exequente. A constatação de que se encontram previamente dispostos em lei, bem como o fato da aquiescência do exequente ser desnecessária, não afasta a natureza de negócio jurídico, pois ainda assim haverá exercício da autonomia privada pelo executado ao apresentar o seu requerimento ${ }^{43}$.

A aplicabilidade do parcelamento se encontra restrita à execução de título executivo extrajudicial. Se na codificação anterior se debatia a sua admissibilidade em relação ao cumprimento de sentença ${ }^{44}$, o Código de Processo Civil atual expressamente dispôs a sua inaplicabilidade ao cumprimento de sentença (CPC, art. 916, § $7^{\circ}$ ). Conforme bem expôs Rodrigo Barioni, o fundamento desta distinção é a amplitude cognitiva dos embargos do executado, que pode ocasionar maiores atrasos à marcha processual ${ }^{45}$.

À luz das normas especiais vigentes em relação à execução por precatório contra a Fazenda Pública, não se pode admitir a aplicação do parcelamento previsto pelo art. 916 do Código de Processo Civil, pois haveria violação do regime estabelecido pela Constituição. Os entes públicos já dispõem de prazo diferenciado para a satisfação das execuções, na medida que o pagamento dos precatórios apresentados até $1^{\circ}$ de julho pode ser realizado até o final do exercício seguinte $\left(\mathrm{CF}\right.$, art. $\left.100, \S 5^{\circ}\right)$, o que poderá implicar em intervalo de até vinte e nove meses para a satisfação da execução, após a expedição do precatório. Além disso, o art. 100, $\S 10^{\circ}$ da Constituição estabelece que tratando-se de precatório com valor superior a $15 \%$ (quinze por cento) do montante dos precatórios apresentados, $15 \%$ (quinze por cento) do valor deste precatório será pago até o final do exercício seguinte, e o restante em parcelas iguais nos cinco exercícios subsequentes, acrescidos de juros de mora e correção monetária. Por outro lado, a Constituição estabelece regime especial, de natureza transitória,

\footnotetext{
${ }^{42}$ DIDIER JR., Fredie. CABRAL, Antônio do Passo. Negócios jurídicos processuais atípicos e execução. In.: Revista de Processo. São Paulo: Revista dos Tribunais, 2018, ano 43, nº. 275, Janeiro-2018, p. 203. FARIAS, M. K. Op. cit. p.433/435.

${ }^{43}$ FARIAS, M. K. Op. cit. p. 435. "Portanto, duas conclusões podem ser extraídas: inicialmente, existem os negócios processuais atípicos, os quais podem ser livremente negociados pelas partes e, portanto abarcam todas as zonas de liberdade, possuindo, assim, espectro mais amplo; e existem os negócio processuais típicos, legalmente pré-estabelecidos, nos quais a liberdade das partes é restrita com relação à possibilidade de negociação dos seus termos e disciplina dos seus efeitos. Todavia, ainda que somente reste ao sujeito a faculdade de praticar ou não o ato, tal fato não desqualifica o ato como negócio jurídico processual”.

${ }^{44}$ Na vigência do Código de Processo Civil de 1973, Alexandre Câmara e Athos Gusmão Carneiro sustentaram a incidência do parcelamento ao cumprimento de sentença. CARNEIRO, A. G. Op. cit. p. 233. CÂMARA, Alexandre Freitas. A nova execução de sentença. $6^{\text {a }}$ ed. Rio de Janeiro: Lumen Juris, 2009, p. 155/156.

${ }^{45}$ BARIONI, Rodrigo. O parcelamento do crédito do exequente no novo CPC. In.: Revista de Processo. São Paulo: Revista dos Tribunais, 2015, ano 40, n. 244, Junho-2015, p. 163.
} 
que à semelhança dos arts. 33, 78 e 97 do ADCT prevê condições especiais de pagamento aos estados, distrito federal e municípios que se encontravam em mora no pagamento de seus precatórios em 25 de março de 2015 (ADCT, art. 101).

Portanto, em relação à execução por maior quantia fundada em título executivo extrajudicial, realizada através da expedição de precatório, a prática de atos sub-rogatórios sob o patrimônio público apenas seria possível quando descumpridos os prazos fixados pela Constituição, que são superiores a seis meses. Deste modo, eventual aplicação do parcelamento previsto no art. 916 do Código de Processo Civil, criaria hipótese não prevista pelo texto constitucional para a satisfação das execuções por maior quantia, em frontal violação aos arts. 100, caput, da Constituição e 101 do ADCT. Ademais, também poderia implicar em subversão da ordem de pagamento dos precatórios, ao permitir ao ente público escolher quais credores receberiam primeiro, ainda que se considere os pagamentos realizados antes da expedição do precatório ${ }^{46}$. Por fim, seria inócua, pois não haveria nenhum incentivo para que a Fazenda Pública, de boa-fé, se valesse de sua aplicação, na medida em que esta dispõe de prazos mais elásticos assegurados pela própria Constituição.

Contudo, é diferente a hipótese da execução por menor quantia fundada em título executivo extrajudicial, onde há a expedição de requisição de pequeno valor pelo juiz da causa, e não de precatório pelo presidente do tribunal. Sujeitam-se à expedição de requisição de pequeno valor as execuções cujo valor não ultrapasse 40 (quarenta) salários-mínimos, para estados e Distrito Federal, e 30 (trinta) salários-mínimos para municípios, caso não exista lei própria, nos termos do art. $97, \S 11^{\circ}$ do ADCT. A execução dos valores que não superam esse teto, vedada a expedição de precatório complementar $\left(\mathrm{CF}\right.$, art. $\left.100, \S 8^{\circ}\right)$, deverá ser satisfeita no prazo máximo de dois meses, contado da entrega da ordem de requisição judicial à autoridade citada para a causa, independentemente da expedição de precatório (CPC, art. 525, § $3^{\circ}$, inciso II). Em tais hipóteses, em que a própria Constituição excepciona o regime de precatórios $\left(\mathrm{CF}\right.$, art. $\left.100, \S 6^{\circ}\right)$, e estabelece um procedimento

\footnotetext{
${ }^{46}$ Contudo, ressalto que a doutrina majoritariamente se posiciona pela inexistência de violação ao princípio da isonomia quando o acordo e pagamento ocorre antes após o ajuizamento da ação, mas antes do trânsito em julgado. Atenta Flávio Willeman que para que não exista ofensa à isonomia os recursos utilizados para o pagamento do acordo administrativo não pode ser objeto de rubricas orçamentárias destinadas ao pagamento de precatórios judiciais. WILLEMAN, Flávio de Araújo. Acordos administrativos, decisões arbitrais e pagamentos de condenações pecuniárias por precatórios judiciais. In.: SOUTO, Marcus Juruena Villela. Direito Administrativo. Estudos em homenagem a Francisco Mauro Dias. Rio de Janeiro: Lumem Juris, 2009, p. 351.
} 
próximo ao das execuções em face de particulares, não há, para nós, impossibilidade de que o ente público possa, durante o prazo para embargos, pleitear o parcelamento, pois inexiste incompatibilidade entre o regime da execução por menor quantia e o parcelamento do Código de Processo Civil (art. 916). O legislador tão só estabelece um prazo máximo de dois meses, a partir do qual, caso não seja satisfeita pela Administração Pública, será expedida ordem de sequestro $^{47}$ (Lei $\mathrm{n}^{\circ} .10 .259$ de 2001, art. 17, $\S 2^{\circ}$ e Lei $\mathrm{n}^{\circ} .12 .153$ de 2009, art. 13, $\left.\S 1^{\circ}\right)$.

Do mesmo modo, nada impede que o ente público celebre negócio processual atípico com o exequente, de modo a ampliar o número de parcelas para satisfação da execução, desde que preenchidos os requisitos do negócio processual, bem como observados os princípios que regem a Administração Pública, tais como legalidade, impessoalidade, moralidade, publicidade e eficiência ${ }^{48}$. Deste modo, conforme bem atenta Fernando Gajardoni, exige-se ainda que de forma genérica, autorização legislativa para a celebração de negócios processuais ${ }^{49}$.

A utilização do parcelamento previsto no art. 916 do Código de Processo Civil pela Fazenda Pública não é desprovida de utilidade prática, pois caso o ente público não realize o pagamento no prazo de dois meses, contado da entrega da ordem de requisição, poderá haver o sequestro de dinheiro público, o que pode comprometer o desempenho de atividades essenciais, especialmente no caso de entes federados de menor arrecadação. Deste modo, o ente público poderá ter interesse jurídico em valer-se do parcelamento estabelecido pelo art. 916 do Código de Processo Civil, na medida em que permitiria a satisfação da execução em prazo superior aos dois meses previstos no art. 535, § $3^{\circ}$, inciso II do Código de processo Civil. Ademais, não haveria o óbice existente na execução por maior quantia, onde há necessidade de se observar as normas estabelecidas pelo art. 100 da Constituição.

A admissão do parcelamento não implicará em violação ao princípio da isonomia entre os credores na atividade satisfativa, nem da moralidade administrativa, pois realizado

\footnotetext{
47 Já apontamos a impropriedade da expressão sequestro, pois tal termo designa medida que busca proteger futura execução para entrega de coisa certa, sendo tecnicamente mais correto nomeá-la de arresto. CANTOARIO, D. M. F. Sequestro..., p. 196/197.

${ }^{48}$ CIANCI, Mirna. MEGNA, Bruno Lopes. Fazenda Pública e negócios jurídicos processuais no novo CPC: Pontos de partida para o estudo. In.: CABRAL, Antônio do Passo. NOGUEIRA, Pedro Henrique. Negócios Processuais. $3^{\text {a }}$ ed. Salvador: Juspodivm, 2017, p. 671.

49 GAJARDONI, Fernando da Fonseca. Convenções processuais atípicas na execução civil. In.: Revista Eletrônica de Direito Processual, Rio de Janeiro, v. 22, nº. 1, janeiro/abril 2021, p. 292.
} 
Rio de Janeiro. Ano 15. Volume 22. Número 3. Setembro a Dezembro de 2021

Periódico Quadrimestral da Pós-Graduação Stricto Sensu em Direito Processual da UERJ

Patrono: José Carlos Barbosa Moreira (in mem.). ISSN 1982-7636. pp. 263-287 www.redp.uerj.br

o depósito de $30 \%$ pelo ente público, o juiz expedirá a requisição de pequeno valor, e a execução será satisfeita de modo parcelado. Caso não realizados os depósitos mensais, será possível a prática de atos de sub-rogação sob o patrimônio público.

Do mesmo modo, a aplicação do parcelamento em relação às execuções por menor quantia fundadas em título executivo extrajudicial não viola o direito à execução das decisões judiciais. Em primeiro lugar, permite que a tutela do direito material consubstanciado no título executivo ocorra de forma célere, na medida em que há renúncia pelo executado dos embargos. Por fim, assegura o respeito à igualdade na previsão abstrata dos meios executivos, de modo a evitar tratamento diferenciado não justificado em face dos entes públicos executado.

\section{Limitações ao sequestro de verbas públicas e a pandemia de COVID-19}

$\mathrm{O}$ sequestro é medida de natureza jurisdicional e satisfativa, que se destina a satisfazer a execução pelo exequente preterido, quando ocorrer desrespeito à ordem cronológica dos precatórios (art. 100, § 6 , Constituição); satisfazer as parcelas não adimplidas previstas nos artigos $78, \S 4^{\circ}$, e $97 \S \S 6^{\circ}, 7^{\circ}, 101$ do ADCT; satisfazer requisições de pequeno valor, quando não tenha ocorrido a satisfação da execução no prazo legal (Lei $\mathrm{n}^{\mathrm{o}} .10 .259$ de 2001, art. 17 e Lei $\mathrm{n}^{\mathrm{o}} .12 .153$ de 2009, art. 13, § $1^{\text {o }}$ ); ou satisfazer execuções dos credores de precatórios vencidos, no caso de não alocação do valor necessário ao adimplemento dos créditos não sujeitos ao regime especial do art. 101, caput do ADCT (art. 104, inciso I, do ADCT) ${ }^{50}$.

Conforme atenta parte da doutrina, a denominação "sequestro", utilizada pelo legislador, não é adequada, pois tal termo designa medida que busca proteger uma futura execução para entrega de coisa certa ${ }^{51}$. Mais apropriado seria nomeá-la de arresto, que de

\footnotetext{
${ }^{50}$ Sobre o tema ver: CANTOARIO, Diego Martinez Fervenza. Sequestro de verbas públicas após as decisões do STF nas Ações Diretas de Inconstitucionalidade 2.362, 4.357, 4.372, 4.400 e 4.425. In.: Revista de Processo, São Paulo, Revista dos Tribunais, nº. 226, Dezembro/2013, p. 195/232.

${ }^{51}$ SILVA, Américo Luís Martins da. Precatório requisitório e requisição de pequeno valor (RPV). $4^{\mathrm{a}}$ ed. São Paulo: Revista dos Tribunais, 20011, p. 250. CÂMARA, Alexandre Freitas. Lições de Direito Processual Civil. v. II. $14^{a}$ ed. Rio de Janeiro: Lumen Juris, 2007, p. 365. CUNHA, Leonardo José Carneiro da. A fazenda pública em juízo. $8^{\mathrm{a}}$ ed. São Paulo: Dialética, 2010, p. 318. "O referido sequestro nada mais é do que um arresto, sendo imprópria a designação de sequestro. Tal arresto, contudo, não ostenta a natureza de medida cautelar, consistindo numa medida satisfativa, de natureza executiva, destinada a entregar a quantia apreendida ao credor preterido em sua preferência". SILVA, Ovídio A. Baptista da. Curso de processo civil: processo cautelar (tutela de urgência). v. 2. $4^{\mathrm{a}}$ ed. Rio de Janeiro: Forense, 2009, p. 205. "Ao contrário do arresto, que se destina
} 
acordo com a definição trazida por Ovídio Batista, "consiste na apreensão judicial de bens do presumível devedor, feita a requerimento de alguém que se afirme seu credor, para segurança de alguma pretensão de natureza monetária, ou específica, tornada impossível de execução in natura" ${ }^{\circ 2}$.

O sequestro coloca em xeque dois pilares do regime dos precatórios: a impenhorabilidade dos bens públicos e a separação de poderes. No primeiro caso, a possibilidade de constrição de verbas públicas torna evidente que não há uma impossibilidade a priori de execução direta contra os entes públicos. Por outro lado, essa mesma execução forçada demonstra que não há uma crise entre os poderes a ponto de afastá$1 \mathrm{l}^{53}$. Em suma, conforme feliz síntese de Cassio Scarpinela Bueno, o sequestro constitucional confirma que o precatório é "muito mais mito do que realidade" 54 .

Se na execução por maior quantia é incomum a efetivação do sequestro de verbas públicas, em relação às requisições de pequeno valor a apreensão de dinheiro público tem sido medida eficaz para assegurar a efetividade da tutela jurisdicional executiva, na medida em que permite o exercício de atos sub-rogatórios pelo magistrado, quando não satisfeita a execução no prazo legal.

Contudo, tem sido escasso o debate quanto à possibilidade de suspensão dos atos sub-rogatórios quando presentes situações excepcionais, tal como a atual pandemia de COVID-19, que causou severos impactos econômicos no mundo todo ${ }^{55}$.

\footnotetext{
a assegurar uma futura execução monetária ou, genericamente, execução sobre coisa fungível, o seqüestro tem por fim proteger uma futura execução para entrega de coisa certa. Por outras palavras, enquanto o arresto tem deve incidir sobre bens de propriedade do arrestado, quaisquer que eles sejam, o seqüestro deve incidir sobre bem determinado, devidamente caracterizado pelo seqüestrante, cuja propriedade ou posse em geral é duvidosa, já que o litígio a ser tratado na demanda principal - de que o seqüestro seja medida preparatória ou incidente - determinará a quem pertence o objeto seqüestrado, ou a qual dos litigantes caberá a respectiva posse".

${ }_{52}$ SILVA, O. A. B. Curso..., v.II, p. 191.

${ }^{53}$ De certa maneira, é o que se pode extrair dos comentários de Ricardo Perlingeiro Mendes da Silva. SILVA, Ricardo Perlingeiro. Execução contra a Fazenda Pública. São Paulo: Malheiros, 1998, p. 127.

${ }^{54}$ BUENO, Cassio Scarpinella. Execução por quantia certa contra a Fazenda Pública - uma proposta atual de sistematização. In: SHIMURA, Sérgio. WAMBIER, Teresa Arruda Alvim (Coord.). Processo de execução. São Paulo: Revista dos Tribunais, 2001, p. 153.

${ }^{55}$ SHWAB, Klaus. MALLERET, Thierry. COVID-19: The Great Reset. Forum Publishing, 2020, p. "The shock that the pandemic has inflicted on the global economy has been more severe and has occurred much faster than anything else in recorded economic history. Even in the Great Depression in the early 1930s and the Global Financial Crisis in 2008, it took several years for GDP to contract by $10 \%$ or more and for unemployment to soar above $10 \%$. With the pandemic, disaster-like macroeconomic outcomes - in particular exploding unemployment levels and plunging GDP growth - happened in March 2020 over the course of just three weeks. COVID-19 inflicted a crisis of both supply and demand that led to the deepest dive on record for the global economy for over 100 years".
} 
Desta forma, a regra geral tem sido o bloqueio de verbas públicas imediatamente após o decurso do prazo de dois meses para a satisfação da execução, ainda que alegado pelo executado a impossibilidade de satisfazer a execução sem comprometer serviços públicos essenciais $^{56}$. Neste sentido, confrontados com pedidos de suspensão do pagamento de requisições de pequeno valor, muitos tribunais de justiça têm negado a suspensão da execução sob o fundamento de que os efeitos financeiros das ações de combate e controle da curva epidemiológica da pandemia de COVID-19, por si só, não justificam a medida ${ }^{57}$, ou de que nas hipóteses de crédito alimentar, prevaleceria o direito do exequente ao recebimento dos valores ${ }^{58}$.

É necessário que a efetividade do direito à execução das decisões judiciais seja analisada à luz da eficácia dos direitos fundamentais. Essa abordagem implica na necessidade de preservar o seu núcleo essencial, e não comprometer totalmente a integridade do direito protegido, quando ocorrer colisão com outros direitos fundamentais. Deste modo, em situações em que se verifica a absoluta, ou potencial, ausência de recursos públicos para a satisfação das execuções lato sensu contra os entes públicos, é necessário que se analise da compatibilidade da medida de suspensão das execuções por menor quantia com o direito à execução das decisões judiciais.

Assim, mostra-se imprescindível analisar a suspensão das execuções à luz das três máximas parciais da proporcionalidade, quais sejam, adequação, necessidade e proporcionalidade $s c r i t u$ sensu $u^{59}$.

A adequação, que consiste na aptidão do meio para alcançar o resultado, encontra-se presente no caso. A suspensão das execuções por menor quantia, no contexto de eventos excepcionais, que causem relevante impacto orçamentário, como é o caso da pandemia de COVID-19, poderá permitir a prestação de serviços essenciais enquanto perdurar a situação

\footnotetext{
${ }^{56}$ BRASIL. Tribunal de Justiça do Estado do Amazonas. Relator(a): Des. Maria do Perpétuo Socorro Guedes Moura. Órgão julgador: Segunda Câmara Cível. Agravo de instrumento nº. 4003258-64.2020.8.04.0000. Manaus: 14/12/2020.

${ }^{57}$ BRASIL. Tribunal de Justiça do Estado do Amazonas. Relator(a): Des. Maria do Perpétuo Socorro Guedes Moura. Órgão julgador: Segunda Câmara Cível. Agravo de instrumento nº 4003258-64.2020.8.04.0000. Manaus: 14/12/2020.

${ }^{58}$ BRASIL. Tribunal de Justiça do Estado de São Paulo. Agravo de Instrumento 2149958-31.2020.8.26.0000; Relator (a): José Maria Câmara Junior. Órgão Julgador: $8^{a}$ Câmara de Direito Público. São Paulo: 24/07/2020. BRASIL. Tribunal de Justiça do Estado de Minas Gerais. Agravo de Instrumento no. 1.0000.20.047286-8/001. Órgão julgador: $6^{a}$ Câmara Cível. Relator(a): Des.(a) Corrêa Junior. Belo Horizonte: 28/07/2020.

${ }^{59}$ MARTENET, Vincent. Géométrie de l'égalité. Zurich-Bâle-Genève:Schulthess. 2003, p. 192/319.
} 
excepcional. O fundamento não é meramente retórico, como se verifica a partir da decisão do Supremo Tribunal Federal que, sob o fundamento da necessidade de manter serviços públicos essenciais, bem como assegurar pagamento de salários, em contexto agravado pela pandemia de COVID-19, manteve o Estado do Rio de Janeiro no regime de recuperação fiscal previsto na Lei Complementar Federal no .159 de $2017^{60}$.

Da mesma maneira, a necessidade também é verificada, pois a suspensão temporária, por prazo razoável, constitui o meio menos gravoso para assegurar a continuidade das atividades da Administração Pública. Tal medida se mostra mais adequada do que o deliberado não cumprimento da ordem de sequestro, que poderá ocorrer quando não houver valores em conta corrente, ou a penhora de valores que seriam destinados a manutenção de serviços públicos essenciais.

Por fim, a proporcionalidade em sentido estrito demonstra que os danos causados aos exequentes são reduzidos, pois implicará em retardo na satisfação da execução que variará entre alguns meses e um ano, o que se mostra relevante quando se trata de assegurar condutas estatais necessárias para efetivar outros direitos fundamentais.

Deve-se atentar que as a jurisprudência da Corte Interamericana de Direitos Humanos, que deve ser observada pelos estados membros em razão da obrigatoriedade do controle de convencionalidade pelos juízes e tribunais brasileiros ${ }^{61}$, estabelece a obrigatoriedade do cumprimento das decisões judiciais em prazo razoável ${ }^{62}$. No caso das execuções por menor quantia, consideradas as particularidades do caso concreto, mostra-se evidente que a postergação da satisfação da execução pelo período em que perdurar a pandemia não se mostra violadora da razoável duração do processo.

Outros países, mesmo em situações distintas da atual pandemia de COVID-19, conferem maior flexibilidade aos entes públicos na satisfação das execuções. Deste modo, na França, a Lei de 12 de abril de 2000, em seu art. 17, estabelece que, no caso de condenações pecuniárias, o prazo máximo para o pagamento é de dois meses, quando existirem créditos

\footnotetext{
${ }^{60}$ BRASIL. Supremo Tribunal Federal. ACO no. 3558/SP. Brasília, 30/12/2020.

${ }^{61}$ MAZZUOLI, Valério de Oliveira. O controle jurisdicional da convencionalidade das leis no Brasil. In.: SOUSA, Marcelo Rebelo. QUADROS, Fausto de. OTERO, Paulo. PINTO, Vera-Cruz (Org.). Estudos em homenagem ao Professor Doutor Jorge Miranda. Coimbra: Coimbra editora, 2012, v.3, p. 768.

${ }^{62}$ CORTE INTERAMERICANA DE DIREITOS HUMANOS. Caso Valle Jaramillo e outros, par. 155; Caso Radilla Pacheco, par. 244; Caso Comunidade Indígena Xákmok Kásek versus Paraguai. Mérito, Reparações e Custas. Sentença de 24 de agosto de 2010. Série C, n. 214, par. 133.
} 
disponíveis "em caixa", e quatro meses, "quando os fundos forem insuficientes" $"$. Verificase, portanto, que mesmo na França, se admite tratamento diferenciado aos antes públicos fundado na disponibilidade orçamentária.

Deve-se destacar que a medida de suspensão da satisfação das execuções por maior quantia foi objeto de apreciação perante o Supremo Tribunal Federal, que autorizou, em sede de tutela provisória, que o Estado de São Paulo suspendesse a execução do plano de pagamentos de precatórios no que se refere às parcelas pendentes do exercício de 2020 . $\mathrm{Na}$ mesma decisão, proferida pelo Ministro Luiz Fux, foi determinada que fosse comprovada a aplicação integral dos recursos no custeio das ações de prevenção, contenção e enfrentamento à pandemia de COVID-1964. A decisão merece atenção pois suspendeu execuções que já sofrem o parcelamento previsto constitucionalmente, ou seja, submetemse a procedimento menos célere do que as execuções por menor quantia, mas nada dispôs em relação à satisfação das requisições de pequeno valor. Portanto, ao nosso ver, se há o reconhecimento, pelo Supremo Tribunal Federal, da proporcionalidade da medida de suspensão da satisfação das execuções por maior quantia, com maior razão se deve admitila em relação às execuções por menor quantia.

Portanto, verifica-se que a suspensão das execuções contra a Fazenda Pública não é estranha ao nosso ordenamento, pois reconhecida até mesmo pelo Supremo Tribunal Federal.

Deste modo, mostra-se imprescindível conciliar, durante a vigência de eventos extremos, tais como a atual pandemia de COVID-19, o direito fundamental à execução das decisões judiciais com as demais prestações que devem ser asseguradas pelo Estado, como aquelas nas áreas de saúde e educação.

\section{Conclusão}

Após a breve exposição é possível concluir que as requisições de pequeno valor possuem grande importância para assegurar o efetivo acesso à justiça do jurisdicionado, na medida em que permite que a tutela de direitos, que normalmente não seriam levados ao Poder Judiciário, possam ser tutelados.

63 RICCI, Jean-Claude. Contentieux administrative. 2. ed. Paris: Hachette, 2007. p. 223.

${ }^{64}$ BRASIL. Supremo Tribunal Federal. Relator: Min. Nunes Marques. Tutela provisória na ação cível originária $\mathrm{n}^{\circ}$. 3.458/SP. Brasília, 30 de dezembro de 2020. 
Da mesma forma, a sua não submissão à ordem própria de pagamento, bem como a admissão do parcelamento do art. 916 do Código de Processo Civil, não violam o direito à execução das decisões judiciais, pois não implicam e tratamento diferenciado não justificável aos exequentes e executado. No primeiro caso, não há prejuízo para os exequentes, na medida em que não satisfeita a execução, no prazo de dois meses, será possível valer-se do sequestro. Na segunda hipótese, não fundamento que afaste o instituto aplicável aos demais executados do regime da execução por menor quantia, e subtrair a sua aplicação dos processos envolvendo os entes públicos consistiria em tratamento diferenciado não justificável - e, portanto, discriminatório.

Por fim, é imperioso conciliar o direito à execução das decisões judiciais com o funcionamento de serviços públicos básicos, quando presentes situações de natureza excepcional, que comprometam sistematicamente a prestação de serviços públicos essenciais. A suspensão das execuções, nestas hipóteses, não será violadora do direito à execução das decisões judiciais, desde que o prazo de suspensão seja razoável, e se restrinja ao período do evento que a motivou.

\section{REFERÊNCIAS}

ÁVILA, Humberto. Teoria dos Princípios. São Paulo: Malheiros, 2007.

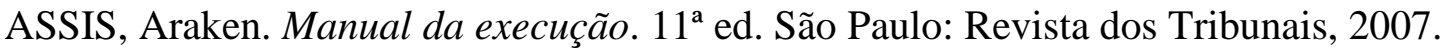

BUENO, Cassio Scarpinella. Execução por quantia certa contra a Fazenda Pública - uma proposta atual de sistematização. In: SHIMURA, Sérgio. WAMBIER, Teresa Arruda Alvim (Coord.). Processo de execução. São Paulo: Revista dos Tribunais, p. 109/174, 2001.

CORRÊA, Antonio de Pádua Muniz. Execução direta contra a Fazenda Pública. São Paulo: LTr, 2005.

CIANCI, Mirna. MEGNA, Bruno Lopes. Fazenda Pública e negócios jurídicos processuais no novo CPC: Pontos de partida para o estudo. In.: CABRAL, Antônio do Passo. NOGUEIRA, Pedro Henrique. Negócios Processuais. $3^{\mathrm{a}}$ ed. Salvador: Juspodvm, pp. 649/674, 2017.

CUNHA, Leonardo Carneiro da. A Fazenda Pública em juízo. 17 $7^{\mathrm{a}}$ ed. Rio de Janeiro: 
Forense, 2020.

CÂMARA, Alexandre Freitas. Lições de Direito Processual Civil. v. II. 14 $4^{\mathrm{a}}$ ed. Rio de Janeiro: Lumen Juris, 2007.

CANTOARIO, Diego Martinez Fervenza. Execução por quantia certa contra a Fazenda Pública. $2^{\mathrm{a}}$ ed. Curitiba: Juruá, 2016. . Sequestro de verbas públicas após as decisões do STF nas Ações Diretas de Inconstitucionalidade 2.362, 4.357, 4.372, 4.400 e 4.425. In.: Revista de Processo, São Paulo, Revista dos Tribunais, $n^{\circ}$. 226, p. 195/232, Dezembro/2013.

DIDIER JÚNIOR, Fredie. Subsídios para uma teoria das impenhorabilidades. In.: Revista de Processo, São Paulo, vol. 174, pp. 30-50, agosto de 2009.

CUNHA, Leonardo Carneiro da. BRAGA, Paula Sarno. OLIVEIRA, Rafael Alexandria. Curso de direito processual civil. V. 5. $8^{\mathrm{a}}$ ed. Salvador: Juspodvm, 2018.

. CABRAL, Antônio do Passo. CUNHA, Leonardo José Carneiro

da. Por uma nova teoria dos procedimentos especiais. Salvador: Juspodivm, 2018.

FONSÊCA, Vitor. Requisição de pequeno valor. In: SANTOS, Ernane Fidélis dos.

WAMBIER, Luiz Rodrigues. NERY JR., Nelson. WAMBIER, Teresa Arruda Alvim. Execução Civil: estudos em homenagem ao professor Humberto Theodoro Júnior. São Paulo: Revista dos Tribunais, 2007.

GALDINO, Flávio. Introdução à teoria dos custos dos direitos. Rio de Janeiro: Lumen Iuris, 2005.

GAJARDONI, Fernando da Fonseca. Convenções processuais atípicas na execução civil.

In.: Revista Eletrônica de Direito Processual, Rio de Janeiro, v. 22, nº. 1, p. 283/321, janeiro/abril 2021.

GIORA JÚNIOR, Romeu. Os precatórios. Revista Tributária e de finanças públicas. n. 76, 2007.

GRECO FILHO, Vicente. Da execução contra a Fazenda Pública. São Paulo: Saraiva, 1986.

GUINCHARD, Serge et al. Droit processuel- Droits fondamentaux du procès. 6. ed. Paris: Dalloz, 2011.

LEMOS, Bruno Espiñeira. Precatório. Trajetória e desvirtuamento de um instituto. Porto - 
Alegre: Sergio Fabris, 2004.

LÓPEZ GIL, Milagros. Avances en la ejecución de Sentencias contra la Administración. Navarra: Aranzadi, 2004, p. 32-45.

IANNICELLI, Luigi. I termini di prescrizione e di decadenza per la proposizione della domanda e la sospensione da Covid-19. In.: Rivista di Diritto Processuale. Anno LXXV (Seconda Serie), N. 4, p. 1616/1639, ottobre-dicembre 2020.

JUSTEN FILHO, Marçal. Emenda Constitucional 62/2009: Estado Democrático de Direito e Responsabilidade Civil do Estado. In: JUSTEN FILHO, Marçal. NASCIMENTO, Carlos Valder. Emenda dos precatórios. Fundamentos de sua inconstitucionalidade. Belo Horizonte: Fórum, 2010.

MARINONI, Luiz Guilherme. Tutela inibitória (individual e coletiva). 4. ed. São Paulo: Revista dos Tribunais, 2006.

MARTENET, Vincent. Géométrie de l'égalité. Zurich-Bâle-Genève:Schulthess. 2003.

MAZZUOLI, Valério de Oliveira. O controle jurisdicional da convencionalidade das leis no Brasil. In.: SOUSA, Marcelo Rebelo. QUADROS, Fausto de. OTERO, Paulo. PINTO, Vera-Cruz (Org.). Estudos em homenagem ao Professor Doutor Jorge Miranda. Coimbra: Coimbra editora, 2012, v.3, p. 761/778.

MIRANDA, Gilson Delgado. Execução contra a Fazenda Pública no sistema constitucional brasileiro. In: FUX, Luiz; NERY JÚNIOR, Nelson. WAMBIER, Teresa Arruda Alvim (Org.). Processo e Constituição. Estudos em Homenagem à José Carlos Barbosa Moreira. São Paulo: Revista dos Tribunais, 2006.

MONTEIRO NETO, João Pereira. Execução contra a Fazenda Pública. São Paulo: Tirant lo Blanch, 2020.

NUNES, Castro. Da Fazenda Pública em juízo. Rio de Janeiro: Freitas Bastos, 1950.

OLIVEIRA, Carlos Alberto Alvaro de. O processo civil na perspectiva dos direitos fundamentais. AJURIS, Porto Alegre, v. 29, n. 87, p. 37-49, set. 2002.

RICCI, Jean-Claude. Contentieux administrative. 2. ed. Paris: Hachette, 2007.

SARLET, Ingo Wolfgang. A eficácia dos direitos fundamentais. Porto Alegre: Livraria do Advogado, $3^{\text {a }}$ ed., 2003.

SENADO FEDERAL. Relatório de acompanhamento fiscal. Nº $\mathrm{N}^{\circ}$. Disponível em https://www2.senado.leg.br/bdsf/bitstream/handle/id/578343/RAF45_OUT2020.pdf. 
Revista Eletrônica de Direito Processual - REDP.

Rio de Janeiro. Ano 15. Volume 22. Número 3. Setembro a Dezembro de 2021

Periódico Quadrimestral da Pós-Graduação Stricto Sensu em Direito Processual da UERJ

Patrono: José Carlos Barbosa Moreira (in mem.). ISSN 1982-7636. pp. 263-287

www.redp.uerj.br

Acessado em 5 de janeiro de 2020.

SILVA, Américo Luís Martins da. Precatório requisitório e requisição de pequeno valor $(R P V)$. 4. ed. São Paulo: Revista dos Tribunais, 2011.

SILVA, Ovídio A. Baptista da. Curso de processo civil: processo cautelar (tutela de urgência). v. 2. $4^{\mathrm{a}}$ ed. Rio de Janeiro: Forense, 2009.

SILVA, Ricardo Perlingeiro Mendes da. Redefinição de papéis na execução de quantia certa contra a Fazenda Pública. Revista CEJ, v. 9, nº. 31, pp. 68/74, out./dez 2005.

SOUTO, João Carlos. A União Federal em juízo. 3. ed. Rio de Janeiro: Lumen Juris, 2006. 